Available online at GSC Online Press Directory

GSC Biological and Pharmaceutical Sciences

e-ISSN: 2581-3250, CODEN (USA): GBPSC2

Journal homepage: https://www.gsconlinepress.com/journals/gscbps

(RESEARCH ARTICLE)

\title{
Ecological reliance, biodiversity and pollination potentials in Bangalore urban gardens
}

\author{
Puspha TC ${ }^{1, *}$ and Reddy MS ${ }^{2}$ \\ ${ }_{1}$ Department of Zoology, Maharanis Science College for Women, Palace Road, Bangalore-560001 India. \\ 2 Department of Zoology, Bangalore University, Jnana Bharathi, Bangalore-560056, India.
}

Publication history: Received on 12 August 2019; revised on 05 October 2019; accepted on 11 October 2019

Article DOI: https://doi.org/10.30574/gscbps.2019.9.1.0153

\begin{abstract}
Urban agriculture is an ancient concept that is gaining momentum in the tier II metro cities in connection with urban renewal projects and efforts to mediate urban food deserts. These agriculture efforts represent a potential habitat for pollinator communities within the urban landscape. Pollinator communities are threatened by urban landscape transformation, and bee species, in particular, are in a state of global decline due to various stressors. Urban agriculture has the potential to sustain both human and ecological communities, and the pollinators that visit gardens may provide pollination to plant species in the surrounding area. We investigated the influence of urban land use on pollinator populations in Bangalore to (i) quantify pollinators visiting urban gardens and (ii) compare pollinator frequency and occurrences among urban gardens, vacant lots (abandoned with no management) and manicured lawns. Three sites were chosen around the Bangalore, an urban garden, a lawn, and a vacant lot. Phytometers were used to monitor the frequency of pollination within the sites. We discovered that the amount of pollinator frequency increased with the flora diversity of the lots. With the manicured lawn having the fewest pollinator visits and the managed urban garden having the most pollinator visit. We saw a relationship between human landscaping and the pollinator communities. From this data we have a better understanding of the effect of the urban landscape on pollinators that will lead to a better use of vacant lots and urban spaces within the city of Bangalore.
\end{abstract}

Keywords: Biodiversity; Honeybee; Pollination; Phytometer

\section{Introduction}

Urban development has increased rapidly since the onset of the industrial and agricultural revolutions [1] Rapid urbanization is a global phenomenon in which various habitats are transformed for human use. The habitat of urbanized landscapes is radically altered as surfaces are made impermeable, soil chemistry is altered, heat islands are formed [2], and species are lost [3] For instance, in the early 1900s 10\% of the human population lived in urban areas and the UN predicts that by $2060,66 \%$ of the human population will reside within urban areas. Urbanization is known to have substantial negative effects on species diversity and carbon pools at a global scale [4]. Transforming these urban areas to increase their habitability for humans and to enhance ecological vitality has become a primary objective for urban planning and restoration ecology. An array of positive economic, psychological and social effects of urban gardening have been noted $[1,5,6]$ and urban gardens also serve as potential microhabitats within the urban matrix [6, 7]. This revitalization also plays a role in creating greenspace and resources for pollinators. Envisioning even heavily impacted green spaces in urbanized areas as "novel ecosystems" has been viewed as a promising revolution in restoration ecology [8] and urban gardens may act as "novel" ecosystems from the perspective of pollinators [7, 9] The insects belonging to the order of hymenoptera, in particular the super family apoidea which encompass all species of bees, are important pollinators which are increasingly threatened with multiple stressors [10]. Bee pollination is a virtually irreplaceable

\footnotetext{
${ }^{*}$ Corresponding author

E-mail address: pusphatc@gmail.com
} 
ecosystem service to human agricultural endeavors [9]. In recent times there has been a decline in bee communities in both wild and managed communities resulting in significant losses of pollination services $[9,11,12]$. This decline has been linked to habitat destruction and fragmentation $[10,13]$. Studies have shown local fauna and landscape can play a role in determining pollinator visits [9] and evidence exists suggesting the decline of pollinators is associated with a decline of insect-pollinated plants [14]. Urban gardens both rely upon, and provide habitat and resources for, bees; there have been few attempts to study bee population dynamics and urban agriculture thus making it an exciting field to be studying. Research in urban environments has demonstrated a positive correlation between greens pace composition and pollinator frequency [7]. Lowenstein compared urban "green roofs," natural prairies and traditional greens pace parks and found a high correlation between bee and plant community composition. Indeed, the more diverse the plant community the greater benefit to bees. A separate study set in Chicago (USA) found that pollination services in different socioeconomic neighborhoods differ as the human population density, proportion of surface concrete, and availability of floral resources change. Important environmental factors for bee richness and abundance were a high diversity of flowering plants, amount of grass or herbaceous cover and solar radiation within the areas of neighborhood. In this study we reported that the relationship between human density and bee abundance can be positive as humans often have a direct positive effect upon floral resource availability [7]. The city of Bangalore (Karnataka, Bangalore) is tier II Metro City of INDIA that robust population density and development. In fact, within the past few decades the population of Bangalore has been instantly raised from 84.3 lakh (2011) to 12.951 million (2019) the most recent census. This human population dynamic has led to a city without much of vacant lots. In spite, Bangalore serves as a good model system as there has been a recent surge of urban renewal and urban agriculture projects that coincided with our research to compare different ways vacant lots could be refurbished. By comparing our three sites- standard (managed lawn), an abandoned lot, and a lot that had been transformed into an urban garden site, we will have a better understanding of pollinator and urban landscapes relationship. The objectives of this investigations were to test the hypothesis that (i) the ecological makeup of the surrounding environment would have an effect on the frequency and types of pollinators that visit and (ii) that a positive correlation exists between pollinator frequency and the level of management of the vacant spaces with higher diversity garden sites exceeding both managed lawn and a residential layout parks.

\section{Material and methods}

\subsection{Site Selection}

The experimental design was created using three sites in Bangalore, the first site was located at an urban agriculture plot of University of Agriculture Sciences GKVK Campus. This site was chosen from multiple urban agriculture sites as it held vegetables with flowers that bloomed throughout fall. The second site was a vacant land/Park at Lal bagh Botanical garden. The garden is rich with vegetation and various grasses. This site represents a typical "abandoned lot" in an urban setting. The last site chosen was Indian Institute of Horticultural Science, Rural district of Bangalore. This site was a large mowed lawn that served as a quasi-control and represents a land-use practice that is typical in urban and suburban areas.

\subsection{Sampling}

Sampling was conducted using two complementary observational methodologies: (a) observation of phytometers and (b) modified phytometer walks. Sampling was conducted during similar weather patterns and temperatures throughout September and October at mid-day. The order in which sites were visited was different for each consequent visit.

\subsection{Phytometers}

Phytometers were chosen based upon bloom times and observed pollinator attraction. In addition to bloom times occurring in the data collection time frame, we also choose plants that would tolerate direct sunlight for the full day as none of the sites had shade. Four plants, two of each species, were placed at the sites. One set of plants were placed at a chosen 'edge' of the site while the remaining set was placed at the 'center' or in the case of the urban agriculture site, placed amongst the agriculture rows. The 'edge' plants were a minimum of 3 meters away from sidewalks and roads to ensure that area around the phytometers where consistent with the site flora. Each plant was transferred to a black plastic pot and had the same soil to ensure no ground contamination affected results. Each set was also surrounded with mulch to deter vandalism and combat overheating of the pot. During data collection each set of plants were observed for 10 minutes and then watered. Hymenoptera, Lepidoptera, and other pollinators were recorded. A walking sample from modified phytometer was collected for each site. During the walk hymenoptera and lepidoptera that were observed were counted as well as flies that were observed to be on flowers. The same path was used for each date of collection and was timed to be 15 minutes. The Lal Bagh Botanical garden and IIHR were larger sites with a homogenous 
landscape compared to the urban garden site and thus had similar walk paths. The walking path for homogenous landscapes was a large square, 30 meters by 30 meters, with two of the edges of the box being the edge and center set of phytometers. The GKVK walk path involved walking between the rows of urban agriculture and a path that led to the edge of the lot site. A representation of these sampling paths can be found within (Figure 1).
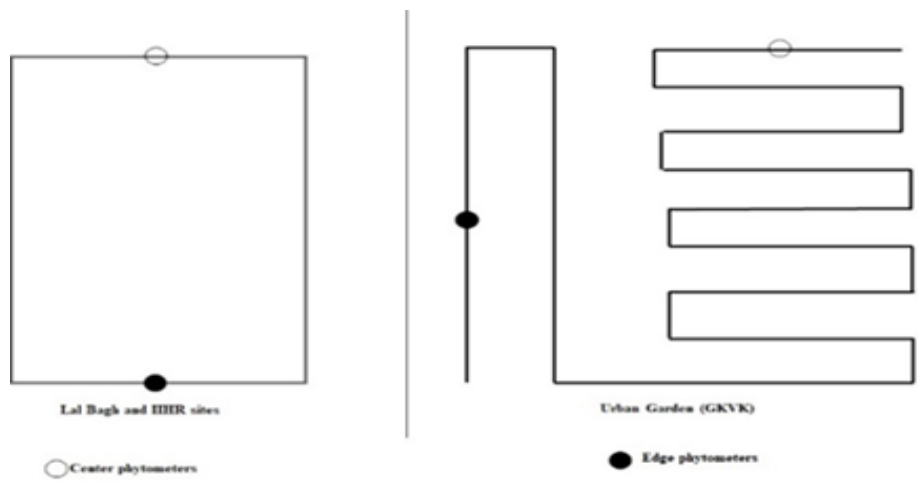

Figure 1 Two different walking paths were determined by the size and terrain of the site. The circles indicate where the phytometers where located the white circle shows and near phytometer while the filled black circle symbolizes the far photometer.

\subsection{Analysis}

Frequency of pollinator visits where found by taking the average of the combination of phytometer and modified phytometer data. All calculations and graphs were made using Microsoft excel.

\section{Results and discussion}

The impact of urbanization upon local ecosystems will continue to grow in the future. Current cities, such as Dayton Ohio, have a large untapped resource in the form of vacant lots that can be transformed into novel ecosystems [8] benefiting organisms cities once pushed out. While past studies in the city of Chicago showed a positive correlation between pollinators and human density [7] our research showed how in the city of Bangalore Urban landscape the care taken towards these green spaces regardless of neighborhood have a large effect on pollinator communities (Figure 2).

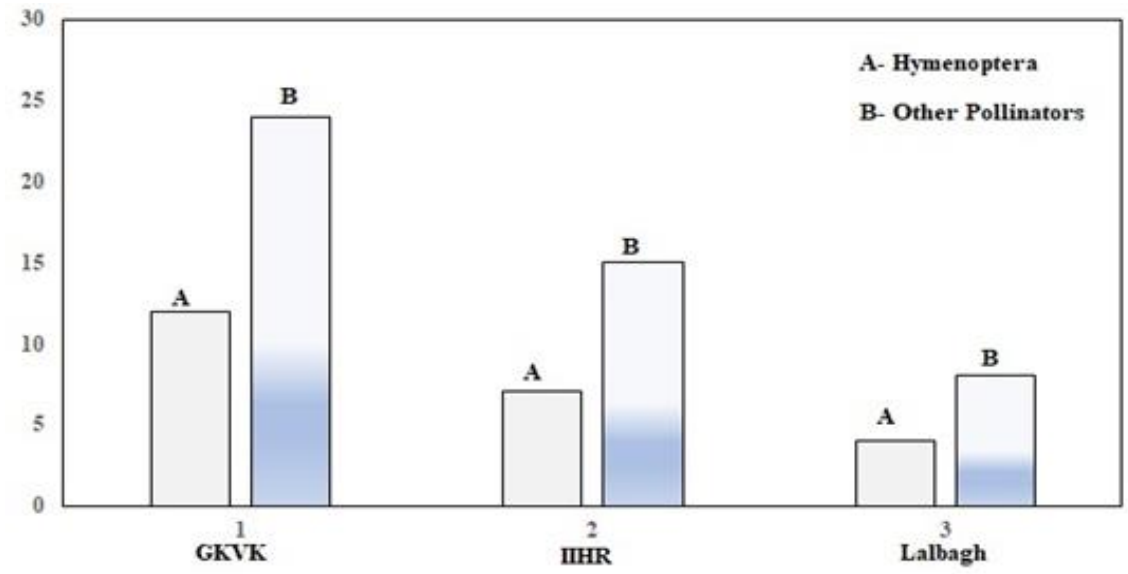

Figure 2 Analysis of average visits by pollinators to site during observation periods

From the data collected we saw there to be a correlation between the various urban landscapes and the pollinator communities. An increase in flowers at the site was related to increase of pollinator visits. The categories for pollinators were broken down into the class hymenoptera, made up of bees and wasps, and 'other' pollinators which were made up of lepidoptera, on flowers and traveling, and diptera, only if on flowers. We discovered a difference in visiting pollinators among our research sites. The urban garden (GKVK) site had the largest number of hymenoptera and other pollinators with an average visit of 11.4 and 24.4 insects, respectively, per data collection (Figure 3). 


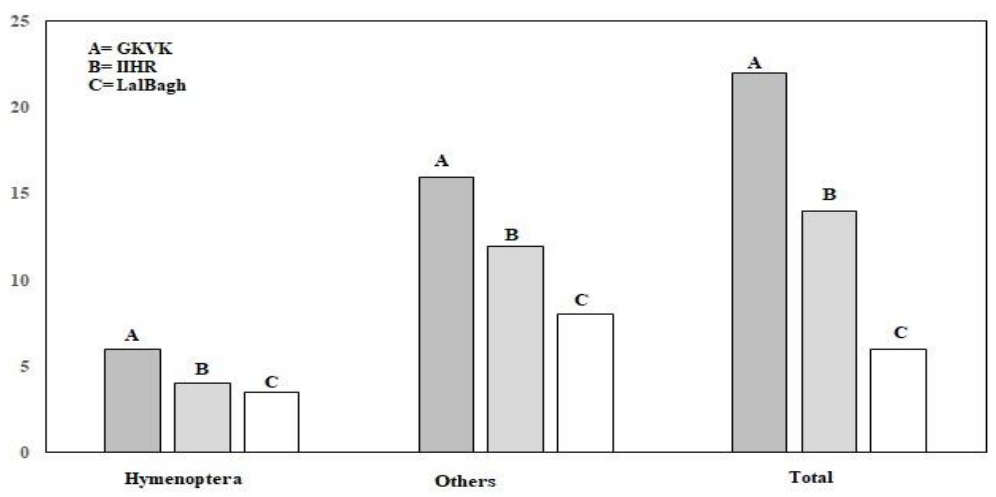

Figure 3 Analysis of average pollinators observed during 15-minute modified walk of phytometer

We found differences between pollinator count during the modified phytometer and during the observations (Figure 3 and 4). The urban garden (GKVK) site again had the greatest amount of pollinator visits across both methods for hymenoptera and pollinators classified as others. Phytometer and modified phytometer walk counts were 6 and 5.4 respectively for pollinators per observation at the urban garden. The Lal Bagh Botanical garden had the lowest observation of hymenoptera with 3.5 for phytometer visits and 0 for the modified photometer walk. We found similar percentages of hymenoptera across two of our sites (Figure 4).

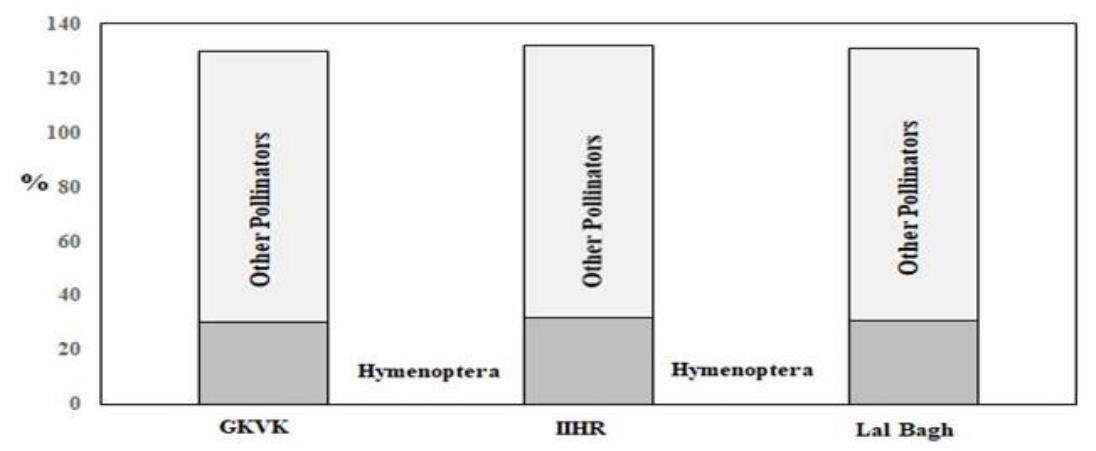

Figure 4 Composition of average pollinator visits to sites during observation

The urban garden (GKVK), Lal Bagh, and IIHR had differing amounts of pollinator visits but proportionally had similar hymenoptera compositions of the community. This was observed from how the urban garden and vacant lot with overgrowth had larger pollinator communities observed then the specified site 3 (IIHR). This correlation gives evidence to support our first hypothesis that the ecological makeup of the surrounding environment does have an effect on the frequency of pollinators that visit sites. From this data we cannot make claims as to whether the pollinator species composition differed greatly across the three sites as we only identified to a basic order, however we did discover that although the frequency of pollinators differed across the sites proportionally all sites had a similar hymenoptera to nonhymenoptera ratio (Figure 4). We also hypothesized that the managed floral urban garden (GKVK) would have a greater pollinator frequency then a site that went unmanaged, the Lal Bagh Botanical Garden. The urban garden (GKVK) did have a higher average pollinator frequency then the vacant lot Lal Bagh Botanical Garden (Figure 4). It was interesting to discover that the composition of pollinators, hymenoptera vs non-hymenoptera, from the two sites were very similar, on average in observation $31.84 \%$ of pollinators where hymenoptera at the urban garden (GKVK) and $34.82 \%$ of the vacant lot's Lal Bagh Botanical Garden pollinators were hymenoptera. An interesting observation was made about the variety of insects at the sites during this early fall experiment. In addition to pollinators, the urban garden (GKVK) had a large number of insects that were not spotted within the Lal Bagh Botanical Garden or IIHR such as grasshoppers and praying mantis. This could be explained by the fact that the urban garden site had a wide arrange of plants from native crops of sunflower, Mango, Phaseolus, broccoli, okra etc., that were not present at other sites. From this study we observed that landscaping in urban cities plays a large role within pollinator communities. Managed sites that have a variety of flowers have a correlation with high pollinator frequency then sites that have unmanaged growth. The city of Bangalore should focus upon their green spaces and transform them into areas that benefit both humans and the insect community. 


\section{Conclusion}

We have observed rapid urbanization upon local ecosystems (Bangalore) the pollinator frequency was increased with the flora diversity in urban garden compare to vacant lots. Which emphasize that the vacant plots should be under proper management with green landscaping which would facilitate the pollinator communities.

\section{Compliance with ethical standards}

\section{Acknowledgments}

Authors expressing sincere thanks to Bangalore University and Maharani Cluster University.

\section{Disclosure of conflict of interest}

Pushpa conducted experiments, M.S Reddy is written the manuscript.

\section{References}

[1] Lawson and Laura. (2005). City Bountiful: A Century of Community Gardening in America. Berkeley: University of California Press Grimm NB,Faeth SH,Golubiewski NE,Redman CL,Wu JG,et al. (2008). Global change and the ecology of cities. Science, 319, 756-760.

[2] Montgomery MR. (2008). The urban transformation of the developing world. Science, 319, 761.

[3] Seto KC, Güneralp B and Hutyra LR. (2012). Global forecasts of urban expansion to 2030 and direct impacts on biodiversity and carbon pools. Proceedings of the National Academy of Sciences, 109(40), 16083-16088.

[4] Foley JA, DeFries R, Asner GP, Barford C, Bonan G, et al. (2005) Global consequences of land use. Science 309, 570-574.

[5] Armar-Klemesu M. (2000). Urban agriculture and food security, nutrition and health. Growing cities, growing food. Urban agriculture on the policy agenda, 99-118.

[6] Lowenstein D, Matteson K, Xiao I, Silva A and Minor E. (2014). Humans, bees, and pollination services in the city: the case of Chicago, IL (USA). Biodiversity \& Conservation, 23(11), 2857-2874.

[7] Hobbs RJ, Arico S, Aronson J, Baron JS, Bridgewater P, Cramer VA, Epstein PR, Ewel JJ, Klink CA, Lugo AE, Norton D, Ojima D, Richardson DM, Sanderson EW, Valladares F, Vilá M, Zamora R and Zobel M. (2006). Novel ecosystems: theoretical and management aspects of the new ecological world order. Global Ecology and Biogeography, 15, $1 \mathrm{e} 7$.

[8] Klein AM, Vaissière BE, Cane JH, Steffan-Dewenter I, Cunningham SA, Kremen C and Tscharntke T. (2007). Importance of pollinators in changing landscape for world crops. Proc. R. Soc. B, 274, 303-313.

[9] Kremen C, Williams NM and Thorp RW. (2002). Crop pollination from native bees at risk from agricultural intensification. Proc Natl Acad Sci, 99, 16812-16816.

[10] Delaplane KS and Mayer DF. (2000). Crop Pollination by Bees. New York, Oxon (CABI Publishing). 352 S., zahlr. s/w Fotos. ISBN 0-85199-448-2 (hardcover). US\$100. Zool. Reihe, 78, 192.

[11] Gallai N, Salles J, Settele J and Vaissière B. (2008). Economic valuation of the vulnerability of the world agriculture confronted with the pollinator decline. Ecological Economics, 68, 810-821.

[12] Rathcke BJ and Jules E. (1994). Habitat fragmentation and plant/pollinator interactions. Curr. Sci., 65, 273-278.

[13] Biesmeijer JC, Roberts SPM, Reemer M, Ohlemüllez R, Edwards M, Peeters T, Schaffers AP, Potts SG, Kleukers R, Thomas CD and Settele J. (2006). Parallel declines in pollinators and insect-pollinated plants in Britain and the Netherlands. Science. 313, 351-354.

\section{How to cite this article}

Puspha TC and Reddy MS. (2019). Ecological reliance, biodiversity and pollination potentials in Bangalore urban gardens. GSC Biological and Pharmaceutical Sciences, 9(1), 115-119. 